\title{
STUDENTS' PROBLEMS OF DEALING WITH LECTURER'S INDIRECT CORRECTIVE FEEDBACK ON ARGUMENTATIVE WRITING
}

\author{
Hasanul Misbah ${ }^{1}$ \\ Fitri Kurniawan ${ }^{2}$ \\ Muhammadiyah University, Jakarta ${ }^{1}$ \\ Muhammadiyah University, Surakarta ${ }^{2}$ \\ Email: misbah.hasanul@gmail.com ${ }^{1}$ \\ Email: fitri.kurniawan@ums.ac.id ${ }^{2}$
}

\begin{abstract}
This study is aimed at describing the problems the students encountered while dealing with the lecturer's indirect corrective feedback on their argumentative writing. This study adapts qualitative approach. The participants involved were 20 fifth semester students of Writing III subject in Jakarta Muhammadiyah University. The study conducted in the period of September-October, 2017. The data were collected using interview and documentation. The data were analysed through Miles and Huberman Model. The results of study showed that students faced problems with: 1) the writing components such as writing content, writing organization, vocabulary, grammar, and mechanics; 2) Writing plan namely, lack of writing preparation and of learning management; 3) Writing process such as ineffective teamwork, big-size class, no background knowledge of the teacher-assigned topics, incomprehensible teaching materials, unreadable and hard to respond feedback, and lack of motivation. The study concluded that students still faced many problems generally with learning writing and specifically of dealing with the feedback and there should be changes of strategy from the feedback to perform better writing progress.
\end{abstract}

Keywords: Argumentative writing, Indirect corrective feedback, Problems of writing

\section{INTRODUCTION}

Argumentation is "a verbal, social, and rational activity aimed at convincing a reasonable critic of the acceptability of a standpoint," by arguing the opposing standpoint (Van Eemeren \& Grootendorst, 2004 , p. 1). In other words, arguments place people to persuade, negotiate, debate, consult, and resolve differences of opinion. In the case of a positive standpoint, the arguments are created to justify and to support ideas based on the standpoint while in the case of a negative standpoint the arguments are to refute or to deny it. Therefore, by starting an argument it should be clear which side is chosen.
Argumentative essay positions a writer to agree or disagree with an issue and attempts him/her to convince the reader(s) with supporting opinion (Oshima \& Hogue, 2006, p. 142). The grounded idea of writer must be clear to see the standing point of the writer. This popular academic writing invites EFL students to think critically and systematically their idea by telling their stand on an issue with solid reasons and evidence. The uniqueness of this writing is that the opposite idea that is probably against the writer's ideas is presented. However, the rebuttal of that opposite idea then is revealed. This action shows the openmindedness of the writers and will lead the 
readers to be more likely accepting writer's point of view.

It must be underlined that teaching argumentative class in EFL setting is not an easy job due to less chance to use language within the environment of the culture around (Brown, 2007, p. 205). Lecturers should consider what students acquire outside the classroom due to the fact that they survive in a strange culture, a different culture from their own culture, as well as learn a language on which they are being "alone" to communicate. The students themselves should be aware of the need of English for their learning success by identifying their internal and external motivation. Besides, Englishbased learning media should be available to support the ELT process for those media such as television, the Internet, and the motion picture industry give access to learn English largely (Brown, 2007, p. 205).

The organization of argumentative writing seems quite simple but the process of creation is uneasy indeed. Oshima\& Hogue (2006, p. 143) structured that an argumentative essay consisted of five keys elements namely, an explanation of the issue, a clear thesis statement, a summary of the opposing arguments, rebuttals to the opposing statements, and writer's own arguments. An explanation of the issue is presented in the very beginning of the writing in the introductory paragraph. This can be presented with engaging introduction such as surprising statistics, a proverb, or a dramatic story. This introduction then should be explained in the second introductory paragraph by telling the issue and writing the thesis statement in the end of paragraph.

The thesis statement indicates which side the writer is for. This is started with the main opposing idea and then completed by the expression of the writer's opinion. In detail, the body of paragraph contains the opposing argument with the rebuttal to argument by describing any kind of reason and evidence. Finally, the writer's point of view is offered to persuade and convince the reader to be in the same ground with the writer.

In learning argumentative writing, beginners need extra attention. They need to gradually be given some feedback of their writing. However, to provide written feedback, most lecturers pay more attention to grammar with less attention to organization and content (Qin \&Karabacak, 2012, p. 95). It is ironic to see how much the learning process spends a plenty of time to discuss the organization and create critical content. Therefore, the feedback which is well-structured should be adapted to represent the objective and incomprehensible assessment.

Qin \&Karabacak (2013, p. 97) proposed that the aspectsof writing can be separated into (a) content; (b) organization; (c) vocabulary; (d) grammar;(e) mechanics; and (f) style. Content focuses on "clearly developed ideas and thoughts;organization on "paragraphs organized logically", "ideas in paragraph in a logicalsequence," "appropriate use of transitions"; vocabulary on "appropriate word choice," "agood variety of academic words"; grammar on "effective complex constructions with noerrors of agreement, tense, number, articles, pronouns, prepositions"; mechanics on"correct spelling, punctuation, and formatting"; style on "correct use of conventions inacademic writing".

Written corrective feedback on students' writing is essential to gettheir writing skills more developed since it contains heavy informational load that providesrecommendations for students' 
better writing and facilitates medium for lecturer andstudent to interact (Hyland \& Hyland cited in Leng, 2014, p. 390). Besides, Aghaei (2013,p. 233) underlined the role of corrective feedback to help EFL students make sure that thelearnt materials were understood or not or have been in their internal memory.

The studentscould argue the learning materials and also evaluate the way they learn. The feedback isgiven to let students review the correction and suggestion from lecturers by reading andcomprehending their problems and then they evaluate it to get their future writingimproved. Hence, the feedback creates chances for the improvement of writing skills.Gradually, the impact can be seen in the future production of written text in which thewriting the students produce contains less errors and gets improved significantly (Leng,2014, p. 390).

Written corrective feedback is commonly divided intotwo major types namely directcorrective feedback and indirect corrective feedback. Direct corrective feedbackis definedas the feedback with a set of explicit correction of linguistic form or structure and itunderlines an unnecessary word/phrase/morpheme, the insertion of a missingword/phrase/morpheme, and correct form or structure (Bitchener\& Ferris, 2012, p. 65).

Direct feedback seems to provide specific solution but itfails to explain what "specificsolution" really means. A solution is specific if it provides a targetlike correction orlinguistic information describing the "cause" of the error and about how it can be corrected(Bitchener\& Ferris, 2012, pp. 131-132).

Indirect corrective feedback indicates an error without providing a correction orexplicit meta-linguistic information and is usually marked in two ways: (1) underlining orcircling an error; (2) recording in the margin the number of errors in a given line (Bitchener\& Ferris, 2012, p. 65). As a result, indirect feedback points out an error in a text withoutproviding solution and let the student decide the possible correction (Bitchener\& Ferris,2012, p. 132). In line with that notion, Lalande (cited in Eslami, 2014, p. 446) indirectfeedback only indicates the existing error without corrective contribution and just let thestudents to find the error. Though debatable, this feedback is assumed to be more effectivebecause it engages students to be in "guided learning and problem solving" (Lalande cited in Eslami, 2014, p. 446) and in "reflection" about linguistic forms that possibly increaselong-term acquisition (Ferris and Roberts, 2001; James, 1998; Reid, 1998 cited in Eslami,2014, p. 446).

Based on the levelof implicitness, there are two types of indirect corrective feedback namely coded correctivefeedback and uncoded corrective feedback. Coded corrective feedback is fulfilled with some symbols that directs students to therelated topic and have them think how to revise. This symbol narrows the possible topics and shortens the students' time to think only related to the topic. Despite its explicitness indirecting the students to the topic, in fact the topic itself still covers some possible errorsthat certainly require students' English knowledge and critical thinking

Uncoded corrective feedback is given on writing by only circling or underlining thewriting errors without any symbols. The error is circled or underlined and the students thenrevise based on their understanding. This type of feedback demands the students spare theirtime to critically reflect and think the right way to 
revise. In fact, big-size classroom mostlyuse this type of feedback on the students' writing because it is more practicable for thelecturer. It will take time for the lecturer to give coded corrective feedback or directcorrective feedback. In fact, studies prove that there was no significant difference betweengroups who got coded corrective feedback and ones who received uncoded feedback (Robet al.; Semke cited in Ahmadi-Azad, 2014, p. 1002).

The tendency of lecturer to use indirect corrective feedback inspired this research to focus on the students' problems of dealing with the indirect corrective feedback on their argumentative essay. Based on the focus of research, the questions of research can be formulated into:

What problems do the students encounter when reflecting the lecturer's indirect corrective feedback?

\section{MATERIALS AND METHODS}

This study adapted qualitative approach. "A case study, an in-depth explanation of a bounded system such as activity, event, process or individuals" (Creswell, p. 125, 2012). The study focused on the process of students' reflection that covered the problems encountered when reflecting the feedback.

The participants involved in this study were the 20 fifth semester students of English Language Teaching Program, Muhammadiyah University of Jakarta who participated in the teaching of Writing III subject. The students were homogeneous in terms of age varied between 18-22 years old, the first language (Indonesia language), and the English education background.

The data sources of the study were the writing products of students' argumentative essay which had been given the feedback for two times by the lecturer and been revised by the students, the interview transcript of students' selfreflection on the lecturer's indirect corrective feedback, the material of argumentative essay adopted from Oshima \& Hogue, and the syllabus of writing III. To gain the required data, the students' argumentative writing, lesson plans, syllabus, and teaching materials were documented. Furthermore, the interview was also done to reveal the research focus namely the problems the students encountered when revising the errors based on the lecturer's indirect corrective feedback.

In analyzing the data, Miles and Huberman Model (Miles \& Huberman, 1994) was used namely data collection, data classification, data coding, data tabulation, data analysis, and data verification. In ensuring the data, method, and sources of data, the writer attempted to monitor the trustworthiness through four components namely credibility, transferability, dependabilty, and confirmability.

\section{RESULTS AND DISCUSSION}

To specify the explanation of findings, the problems were presented in three parts namely: 1) The problems of writing components; 2) The problems of planning to write and; 3) The problems of learning process. The problems of writing components explain the problems students encountered when revising the errors of content, of writing organization, of vocabulary, of grammar, and of mechanics. The problems of planning to write explain the obstacles the students encountered when planning their writing. The last is about the problems the students encountered during the process of learning. 


\section{The Problems of Writing Components}

The problems of writing components contain the phemonena of revision based on the aspects of writing. Those writing aspects are the writing content, organization, vocabulary, grammar, and mechanics. The content and writing organization were given the feedback in the form of circle and end note while the others were only circled.

A lot of content and organization writing were no follow-up of feedback. The writing errors related to the introductory paragraph such as weak introduction of the issue and unavailability of the thesis statement. Regarding those writing errors, the lecturer literally noted "I can't see your position toward the issue" and "you have no clear position". Both notes indicated that the students should revise their writing by giving a thesis statement in their writing. The notes also commented "the introduction was still not clear and gave questionable sentences" that indicated the weak content of introduction. In other words, the students introduced the topics poorly.

Among ten pair groups, there were six groups that had been given feedback on the writing content that noted the weak introduction due to the unavailable thesis statement. Unfortunately, no single group revised their writing as expected. No thesis statement existed in their final writing. The students ignored the feedback. In other words, the feedback did not contribute to the positive revision of students' introductory paragraph. In fact, the groups that could produce a good writing content in their introductory paragraph had no problem with their thesis statement from their first writing.

After conducting interview related to this phenomenon, the students responded, as follows:
"We didn't really understand to revise the errors based on the comment (end note) so that we only revised the circled errors as good as we could. Although we know (understand the feedback) that there was something wrong with our writing idea, we were often confused to figure out the steps to revise."(Interview result with Student NB \& TR)

The feedback on vocabulary is related to the appropriate word choice and a good variety of academic words (Qin \&Karabacak, 2013, p. 97). In this study, the feedback was given only in the form of circle. The materials related to the errors were about collocation, double subject, phrasal verb, repetition, word order and diction/word selection. Diction errors were dominant and the students faced difficulties to deal with them.

The students most of the cases focused on the grammar while revising the vocabulary errors. The lecturer should review the students' intention toward the feedback by training the students how to respond the feedback in the form of circle that might contain many aspects of writing not only grammar. By doing so, the students' response might vary.

The feedback on grammar is related to the "effective complex construction without errors of agreement, tense, number, articles, pronouns, prepositions" (Qin \&Karabacak, 2013, p. 197). There are many materials related to the feedback on grammar namely noun clause, adjective clause, subject verb agreement, word order, complex sentence, parallelism, quantity words, etc. Most of the students could revise any types of grammar error well. Subject verb agreement dominated the grammar errors and most of the students could deal with this error. In some cases, they found it hard to revise the errors related to 
causative, word order, appositives, parallelism, passive sentence and complex sentence.

The feedback on mechanics can be classified as the simplest and most readable feedback because it only focuses on correct spelling, punctuation and formatting (Qin \&Karabacak, 2013, 197). In this study, the lecturer circled the errors related to the mechanics errors. The problem about spelling dominated the feedback on mechanics with several cases of punctuation and a few about formatting. When it dealt with spelling or formatting most of the students could easily revise although found a few exceptional cases. On the contrary, more numbers of error revisions if the feedback was about punctuation. In some cases, the students were careless about their writing, the sentence pattern which at least consists of subject and verb and of punctuations like comma and period.

\section{Problems of Planning to Write}

In fact, the students complained about the lack of preparation in the class. It was worsened by the case of taking some internet articles and writing based on them. They did not make any writing outline that made their writing have a lot of errors due to different writing patterns between the pattern of argumentative essay and of article.The lecturer only explained the theory and discussed an example of argumentative essay. Though the outline of the example was discussed, the students apparently were in need to have personal assistance for making their writing outline. It might positively give extra help for the students to start writing because the outline could be the map or clear direction of what to get through. The process of brainstorming which is vital to green writers were omitted and it caused the students only wrote based on their knowledge and skill.

Besides, there was also a complaint about limited time for revision even though they could finish based on the deadline. There was burden for the limited time for revision and non-lecture activities on campus so that improvement of their writing was not significant.

The students' voice about this phenomenon is commonly passed on but mostly ignored. The students were insisted to adapt the learning process and there was no solution to the problem. The lecturer should continually remind the students to keep on tracks by giving major priority for lectures as their basic purpose on campus. Besides giving a learning task and assistance, the lecturer might warn the studentsto develop more awareness of learning time management. They could be trained or be given tips and strategies to deal with their problems. The lecturer together with the students may design the learning plan and discuss the consequence of being responsible to the learning. It is vital to bear in mind that the more responsible to the learning, the better the learning result. Besides, the lecturer may stimulate the students to self-actualize themselves by giving a reward for the best writing to have their writing published in campus magazine or online learning group.

\section{Problems of Learning Process}

The ineffective teamwork involved the groups that run into difficulties to deal with the act of collaboration like sharing task responsibility and being discipline with the task deadline. Two pair groups admitted that one of each groupwas much more dominant in the group and wrote the whole writing and the other only helped to find the writing sources. Students claimed that the more superior partner in writing 
skill became the main reason why the main actor of writing was only one of them. Other had revealed the different reason. They claimed that not knowing how to share their task effectively was the only reason why they avoided sharing task responsibility. They had no clear strategies. Those cases happened because the partners felt more inferior and all of them did not know how to share their task responsibility effectively.

Those cases showed that though the students had chosen their own partners convincingly it was not guaranteed they would not face technical problems especially ineffective teamwork. Therefore, the lecturer should find the way to deal both with the students' writing and students' interaction in groups.

Big-size class is a classic problem in formal education especially in developing countries that mostly cover more or less thirty until forty students per class. The argumentative class in this study adopted a big-size classroom with 30 students and the complaint about the limited time to interact was commonly uttered. The lecturer could not assist all of the students who mostly have different writing problems.

The students complained about the difficulty to interact with the lecturer because of the big-size class. In addition, the lecturer should consider the questions that possibly correlated with other students' problem. In dealing with this kind of problem, the lecturer should prepare for the common problems students had in their writing and then explain how to deal with those problems before giving the following feedback so that the students could understand the feedback sooner and better. It is much better than letting students in a big-size classroom ask questions randomly that most probably cover the same points of discussion. In doing so, the effective time for problem solving of understanding feedback can be achieved.

This study adopted the random selection of the topics covering several kinds of recent issues happening in Indonesia. The issues were about politics, social life, technology and social media, education, arts, media, sports, economy, and religion. The random selection was chosen to anticipate the homogenous topics that the students proposed when independently selecting the topic. The topics were about: 1 . The political issues namely the plan of revising the statute of national corruption commission (KPK); 2. The social issues namely the Jakarta government plan to legalize prostitution; 3 . The technological and social media issue namely the negative effects of social media; 4. The technology and education issue namely online learning; 5 . The arts and media issue namely the ban of television programs by Indonesia Broadcasting Commission (KPI); 6. The national sport issue namely the temporary termination of the association of national football (PSSI) by national youth and sport minister; 7. The social and economic issue, the ban of imported used clothes trade by national health minister; 8 . The social and religion issue, the ban of smoking for Moslem by Indonesia Scholar Council (MUI); 9. The education issue namely the plan of certification fee abolition for teachers by national education minister; and 10 . The education issue, the plan of dropping out the students doing academic crimes such as cheating and plagiarism.

This kind of approach certainly had impacts on how students dealt with their writing. It was found that no background knowledge of an issue or topic may lead to negative or positive effect to the students' motivation in writing. A new topic could 
possibly attract the attention of students to get through the necessary information for their writing. They were more eager to get immersed with their writing. On the contrary, when the students were not interested in the topic at all, they might give less effort.

There were two primary teaching materials discussed in the learning process. The first was adopted from the chapter 9, Argumentative Essay, of Oshima\& Hogue books entitled "Teaching Academic Writing, fourth edition".The second material, presented in power point, was the summary of students' writing problems found in their first writing and the materials adapted from Qin \&Karabacak Journal (2013) discussing the aspects of writing feedback. The summary of students' writing problems underlined the common errors students had in their writing and the lecturer made some discussion with the students and then suggested some appropriate solutions. The students were introduced to the writing aspects namely writing content, organization, vocabulary, grammar, mechanics, and style and taught how to understand the feedback that concerned on the errors of those writing aspects.

The student perceived that the materials could have been prepared better. The students' language skill and the comprehensiveness of teaching materials should be seriously taken into account. The better learning process and result could possibly happened. Fortunately, the lecturer could figure out the students' understanding of the materials by checking the result of revision. If the materials were understandable, the students would have the better revision. If not, there would be something wrong with the learning aspects and one of them was learning materials.
The indirect corrective feedback with its implicit direction or suggestion applied in this study was much more practical for the lecturer in a big-size classroom. The lecturer expected that the students could read and respond the feedback. However, many cases showed that the students could not respond the feedback well. It was caused not only by the students' incomprehension toward the feedback but also the their confusion to respond.

The class that lack portion of explaining this strategy influenced the number of students who miscomprehended the feedback because they tended to pay less attention to or wrongly revise the feedback. Therefore, before the students started to write, they should be introduced both the materials and the way to respond the feedback. While the learning process, the students also got the follow-up to respond the feedback correctly.

Good internal motivation can produce high confident students. A group of students claimed that their confidence built enthusiasm for asking their problems in the classroom. They were actively consulting the lecturer about the feedback that they could not respond and looking forward to getting lecturer's suggestion. Furthermore, they also compared their writing with their friends' writing. It contributed positively because they got inspired from the writing by learning the correct and incorrect parts.

Otherwise, the students with low internal motivation were less motivated to get involved in the learning process. They already possessed the negative perception of learning process that demanded their eagerness to study.Thus, they needed the situation that stimulated their potential. In short, they needed more external motivation. In fact, it was found students perceiving that the class unsuccessfully 
helped them write. They were insecure to offer any questions. Even more, too many errors marked on their writing also affected their confidence.

\section{DISCUSSION}

To bear in mind, the students actually faced very complex problems in responding the feedback. They were placed in a big-size class and were paired into groups with mostly lack of teamwork. Moreover, they perceived the teaching materials negatively and complained about the less interesting lecturer-assigned topics and unreadable feedback and in short created them less motivated to learn with their real effort. The problems were actually related to each otherand therefore the discussion should present the proper solutions with well structured and constructive description.

In planning the writing, Deane \& Song (2014, pp. 101-102) suggests five phases of argumentation that the writers must pay attention to in order they can be more prepared to write their arguments. The first is to comprehend the stakes. The writers pay attention to the audience and the context. This action is called appeal building, the social reasoning to take over people' belief and action. The words selection and the way to persuade the readers are well considered in this step. Secondly, the students must explore the subject in order to understand the topic widely (Deane \& Song, 2014, p. 101). Third, the students must consider positions that are the most sensible and can easily be supported (Deane \& Song, 2014, p. 101). Fourth, the students should produce and assess their arguments. Effective argument must be valid and have evidence (Deane \& Song, 2014, p. 102). In building arguments, it is more convincing to have reference to support the ideas. For this purpose, the lecturer should warn the students to build their arguments from other clear and strong sources to avoid the weak and unconvincing evidence and statement. In the last place, the students should organize and present arguments(Deane \& Song, 2014, p. 102). Students should have ability to frame a case and be open to assistance from the lecturer.

Besides, the problems of time management appeared where the students could not give give their maximum effort to the writing. Before getting involved in their writing process, the students were in need to manage their learning activities because time management is considered positive to increase the academic performance. Indreica et all. (2011, p. 1102) proposed that the learning programs should also frame the students' personal ability in the field of organizing their learning activity during semesters, organizing learning activity during exams periods, teaching them to organize their program and structuring their weekly learning activities. It is helpful to increase their academic success and motivation.

In process of learning, the students also failed to collaborate with their teammates and lecturer should also be aware of and stay alert to this situation. Donato (cited in Wigglesworth \&Stroch, 2012, p. 367) declared three points of collaboration. First, the students should be used to being in social relations so that the discussion can be effective and meaningful. Second, the students should build their awareness as the part of learning activity in order each student plays a role to achieve the bigger learning goal that can only happen when each of the roles is well-figured. Last but not least, the students should have knowledge and be aware to persistently widen it. The points above suggest that the lecturer should watch out the process of 
collaboration and prepare the students sources or how to find appropriate sources for their writing.The lecturer, the facilitator of learning, should also be in charge to continuously remind the students about the values of collaboration above, be the figure in taking care the possible obstacles happening between students and be open for consultation not only about the technical problem related to the writings but also the students' teamwork. It is in line with the statement from Fahim and Hashtroodi (2012, p. 637) that claim there should be an attempt to re-establish synergy between the activity of learning and the context and students' need. The learning habit for years with a teachercentered instruction without the familiarization of discussions with critical knowledge sharing must be seriously taken into account. The teacher is no more a dominator and not more than a facilitator who colors the class and gives learning instruction without a strict direction of what is allowed or not allowed. The critical thinkers are produced by this kind of class and they the only ones can write argumentative essays well.

Principally, the learning process encourages the students to be aware and feeling satisfied with what they achieve intrinsically. This action, known as selfactualization, fulfills the students' security, identity and self-esteem that Maslow (cited in Brown, 2006, p. 173) believed much more superior to the extrinsic motivation which is related to only the "fundamental physical necessities" such as air, water, or food. Consequently, the class should adapt this approach by giving motivation or situating a more motivating class. This kind of action increases the students' motivation.Ketsman (2012, p. 14) claimed the importance of building learning expectations as the essential factor for students' better achievement. Her study of expectations in foreign language (FL) classrooms proves that a good FL teacher consistently encourages students maximize their abilities and become more motivated.

Moreover, Brown (2007, pp. 9798) suggests that the lecturer are professionally required to have three conditions to be a successful facilitator in the class. First, they need to be real and genuine. They are not necessary to be too superior and to look very knowledgeable in everything in order the students have space to aspire their ideas. Second, a good lecturer should be able to honestly give their trust, acceptance, and prizing of the students. These can make students more worthy as individuals. The last, lecturers should attempt to create an open and emphatic communication with the students. With these classifications, the lecturer can both understand the students more and be effective lecturers who can formulate good learning schema based on the context of learning and achieve the teaching goals.

The findings from Ka-kan-dee\& Kaur $(2015$, p. 151) underlined the need of professional development for the lecturer teaching a big-size classroom. A long work experience may need refreshment to be a more creative lecturer. In fact, in short term period the condition of large classroom size probably could not be changed soon but training for lecturer's professional development may inspire a new creative idea for their teaching in practice and most importantly can contribute positive impacts for the class sooner.

The class adopted teacher-assigned topics became influences the students' eagerness to write. To be fair in the class, the lecturer could design some writing topics and allow students to follow or 
create their own topics with some suggestions. The points that the students should be told are about the benefits of adopting student-self-selected and lecturer-assigned topics. After that, the lecturer should wisely let the students decide the topics they want to choose. This class produces flexible instructional strategies (Bonyadi\&Zainalpur, 2014, p. 391). Finally with this type of strategy the students can keep their learning motivation and are more eager to write better.

There were two major criticisms about the teaching materials. The first was not well-prepared teaching materials. The argumentative materials adopted from Oshima\& Hogue considered appropriate for advanced learners did not suit the class. The students complained about the high language level and inauthentic examples of argumentative writing. Furthermore, the materials about how to read the feedback were also criticized by the students because it lacked authentic examples of responding the feedback. Therefore, the students could not respond the feedback well. Sun (2010, p. 889) claimed that teaching materials influenced the students' motivation and can be analyzed in the term of interest in the subject matter, level of difficulty, relevance to existing knowledge, and perception of usefulness. He found that the teaching materials should be tested in each of above aspects. The appropriate level of difficulty lets the students pay more attention to the class. Personal relevance referred to the students' needs, values, and goals determines the students' attitudes toward learning. The visual material and authentic material are to increase the students' interest and enthusiasm (Sun, 2010, p. 891).

If everything was prepared as above but the students still perceive that the materials was hard to understand, the lecturer needs to explain a simpler argumentative essay. This action is according to the Brown's notion (2007, pp. 97-98) that underlines the need of lecturer's intuition to view the learning and respond the any kind of learning problem in order effective teaching is achievable. However, the lecturer should anticipate this kind of problem by explaining the example in the very first class. It is not only to make them understand but also to build positive attitude toward the lesson.

The feedback given in this study was implicit. However, the problems occurred when they could not understand the feedback or had no idea to respond the readable feedback. Ahmadi et al. (2012, p. 2594) suggested to incorporate both feedback types since it is believed that no single feedback effectively works for all students with different situations and errors. In practice, the lecturer could at first apply indirect corrective feedback for indicating students' writing errors but when the students could not revise the errors especially grammar errors the direct corrective feedback must be applied because probably the students did not learn the related grammar materials yet. Besides, Hosseiny(2014, p. 672) stated that the students need a training from their lecturer about how to deal with the feedback in order they can achieve a positive improvement of their writing. The class that lack portion of explaining this strategy influenced the number of students who miscomprehended the feedback because they tended to pay less attention to or wrongly revise the feedback. Therefore, before the students started to write, they should be introduced both the materials and the way to use the feedback.

Vyatkina (2011, p. 82) mentioned the influence of policies focusing on the way 
to give written corrective feedback in students' writing. It was found that when the kind of written feedback, the strategies adopted and what writing aspects to be noted are up to the instructors' hand, they would hardly found the effective and efficient feedback for the writing and the formula to objectively grade the writing. It was suggested that the writing programs should be managed and coordinated in some areas. First, the clear and specific feedback rubrics for different writing assignment should be formulated and applied specifically in the content and form. Second, there should be an open discussion among the policy makers, curriculum designer and the practitioners in the beginning of each academic year to create general writing policies. Third, a periodic investigation and practice session for the instructors should be performed. Fourth, the discussion about the development of written corrective feedback study should be available in the methodology courses. Furthermore, the instructors should also provide a learning guidance for students in the field of writing plan, strategies for revision, input request from instructors or other groups and more importantly motivation booster due to the fact that they did the revision in last minute (Vyatkina, 2011, p. 83).

\section{CONCLUSION}

In summary, the students faced a variety of problems while revising the errors based on the lecturer's indirect corrective feedback. The problems were related to the students' low writing skill which can seen from how the students got into difficulties while revising the errors related to the writing components namely the content, writing organization, vocabulary, grammar and mechanics. In planning the writing, the students were also hard to make their own writing outline so that they directly started their writing based on the reference they got without any specific plan and concept. In addition, the students could not organize their learning time well because some of them could not meet the deadline with a good revised writing and in fact were involved in students' organization in or outside campus that made them have troubles in organizing their learning time. In learning process, most students were involved in the groups with ineffective teamwork so that only one member of each group dominated the task responsibility. The big size class also made the students feel insecure to consult the lecturer about their learning problems and the situation was worsening due to no background knowledge of the teacherassigned topics, incomprehensible teaching materials, and unreadable and hard to respond feedback that influenced the students' learning motivation. It showed that there were still many problems that the students faced in responding the feedback and those problems contributed negatively to the success of revision.

The lecturer should prepare the students' writing plan, be responsive to students' problems in writing process, and incorporate the direct and indirect feedback. In planning the writing, the lecturer should be discussing the students' learning management to achieve the deadline of writing submission, doing some brainstorming to prepare the outlines of writing, and teaching them how to understand and to respond the feedback well by explaining the example of writing errors and discussing the procedures to respond the feedback. In learning process, the lecturer should respond any kind of problems that may happen. For instance, the lecturer should find the way to solve the ineffective teamwork among the 
groups, big-size class, incomprehensible teaching materials and so on. The lecturer should also provide an effective discussion in which the students are able to consult the lecturer or other students about their writing problems. The discussion itself should be flexible by implementing an open discussion or personal assistance based on the students'personal condition and need. In giving the feedback, the lecturer should incorporate for certain circumstances. The different type of feedback should be given if the related materials were not learnt yet or the previous feedback was ignored so that the students can revise the writing. Furthermore, the feedback should also give spaces for a dialogue between the student and the lecturer. The dialogue is functioned to cover the problems of limited time for consultation in the classroom.

The students should be more motivated in the learning process. They are supposed to actively find the solution to any problems they encountered and to apply the strategies appropriately. They are required to be involved in a good teamwork, to use the learning media under the lecturer's recommendation to avoid the act of plagiarism and lack of creativity in their writing, and to consult the lecturer about their problems in an open discussion or a personal discussion. Due to the implicit correction and direction on the feedback, the students should get used to thinking critically so that they can understand how to respond the feedback well.

\section{REFERENCE}

Aghaei, P. (2013). Learners' Perception toward the Effect of Recast on the Quality of Their Oral Output.
International Journal of Humanities and Social Science, 3, pp. 233-237

Ahmadi-Azad, S. (2014). The Effect of Coded and Uncoded Written Corrective Feedback Types on Iranian Learners Writing Accuracy. Journal of Theory and Practice in Language Studies, 4, pp. 10011008. doi:10.4304/tpls.4.5.10011008

Ahmadi, D., Maftoon, P., \& Mehrdad, A.G. (2012). Investigating the Effect of Two Types of Feedback on EFL Students' Writing. Journal of Social \& Behavioral Sciences, 46, pp. 2590-2595.

doi:

10.1016/j.sbspro.2012.05.529

Bitchener, J. \& Ferris, D.R. (2012). Written Corrective Feedback in Second Language Acquisition and Writing. New York: Routledge Ltd.

Bonyadi, A. \&Zeinalpur, S. (2014). Perceptions of Students Towards Self-selected and Teacher-assigned Topics in EFL Writing. Journal of Social \&Behavioral Sciences, 98, pp. 385-391.doi: 10.1016/j.sbspro.2014.03.430

Brown, H.D. (2007). Principles of Language Learning and Teaching (5thed.). New York: Pearson Education

Broughton, G., Brumfit, C., Flavell, R., Hill, P., \&Pincas, A. (2003). Teaching English as a Foreign Language ( $\left.2^{\text {nd }} e d.\right)$. London: Taylor $\&$ Francis e-Library.

Creswell, J.W. (2012). Research Design: Qualitative, Quantitative, and Mixed 
Methods Approaches. California: SAGE Publications, Inc.

Deane, P. \& Song, Y. (2014). A Case Study in Principled Assessment Design: Designing Assessment to Measure and Support the Development of Argumentative Reading and Writing Skills. Journal of PsicologiaEducativa, 20, pp. 99-108. doi:

10.1016/j.pse.2014.10.001

Eslami, E. (2014). The Effects of Direct and Indirect Corrective Feedback Techniques on EFL Students' Writing. Journal of Social and Behavioral Sciences, 98, pp. 445452.

doi:

10.1016/j.sbspro.2014.03.438

Fahim, M. \& Hashtroodi, P. (2012). The Effect of Critical Thinking on Developing Argumentative Essays by Iranian EFL University Students. Journal of Language Teaching and Research, 3, pp. 632-638. doi:10.4304/jltr.3.4.632-638

Hosseiny, M. (2014). The Role of Direct and Indirect Written Corrective Feedback in Improving Iranian EFL students' Writing Skill. Journal of Social and Behavioral Sciences, 98, pp. $\quad 668-674 . \quad$ doi: 10.1016/j.sbspro.2014.03.466

Indreica, E-S, Cazan A-M, \& Truta, C. (2011). Effects on Learning Styles and time management on Academic Achievement. Journal of Social and Behavioral Sciences, 30, pp. 10961102

Ka-kan-dee, M. \& Kaur, S. (2015). Teaching Strategies Used by Thai
EFL Lecturers to Teach Argumentative Writing. Journal of Social \& Behavioral Sciences,208, pp. $143-156$

Ketsman, O. (2012). Expectations in the Foreign Language Classrooms: A Case Study. Journal of The Qualitative Report, 12, pp. 1-21. http://www.nova.edu/ssss/QR/QR17 /ketsman.pdf

Leng, K.T.P. (2014). An Analysis of Written Feedback on ESL Students' Writing. Journal of Social and Behavioral Sciences, 123, pp. 389397. doi: 10.1016/j.sbspro.2014.01.1437

Miles, M., B. \& Huberman, A., M. (1994). Qualitative Data Analysis: A sourcebook for new methods ( $2^{\text {nd }}$ ed.). Thousand Oaks, CA: Sage.

Oshima, A. \& Hogue, A. (2006). Writing Academic English. London: Pearson Longman Ltd, pp. 142-147

Qin, J., \&Karabacak, E. (2013) Turkish EFL University Instructor' Practices in Providing Written Feedback. Journal of Social and Behavioral Sciences, 70, pp. 95-100. doi: 10.1016/j.sbspro.2013.01.044

Sun, Z. (2010). Language Teaching Materials and Learner Motivation. Journal of Language Teaching and Research, 1(6), pp. 889-892. doi:10.4304/jltr.1.6.889-892

Van Eemeren\&Grootendorst. (2004). A Systematic Theory of Argumentation. Cambridge: Cambridge University Press. 
Vyatkina, N. (2011). Writing Instruction and Policies for Written Corrective Feedback in the Basic Language Sequence. L2 Journal, 3, pp. 63-92

Wigglesworth, G. \& Storch, N. 2012. What Role for Collaboration in Writing and Writing Feedback. Journal of Second Language Writing, 21, pp. 364-374. http://dx.doi.org/10.1016/j.jslw.2012 .09 .005 